\title{
Eritema elevatum diutinum con compromiso cutáneo extenso y laríngeo en un niño
}

Erythema elevatum diutinum with extensive skin and laryngeal involvement in a child: case report

\author{
Tatiana María Restrepo-Castaño¹, Catalina Santa-Vélez², Elsa Bibiana Peña-Zúñiga³, \\ Ana María Muñoz-Monsalve ${ }^{4}$, Delsy Yurledy del Río-Cobaleda5 \\ 1. Médica dermatóloga, Universidad CES, Medellín. Colombia \\ 2. Médica dermatóloga, Universidad CES, Medellín, Colombia, Especialista en Dermatología oncológica, Instituto Nacional de \\ Cancerología, Bogotá, Colombia \\ 3. Médica dermatóloga; especialista en Dermatopatología, Universidad CES, Medellín, Colombia \\ 4. Médica dermatóloga, Universidad Pontificia Bolivariana, Medellín, Colombia \\ 5. Médica dermatóloga; Hospital "Pablo Tobón Uribe”, Medellín, Colombia
}

\section{RESUMEN}

El eritema elevatum diutinum (o eritema elevado persistente o diutino) es una dermatosis inflamatoria crónica rara, caracterizada por pápulas y nódulos eritematosos, de color café o violáceos, localizados en superficies extensoras, con un patrón clínico característico. Generalmente, está asociado a enfermedades infecciosas, autoinmunes o neoplasias hematológicas. Algunos autores lo clasifican como una vasculitis leucocitoclástica; otros, como una dermatosis neutrofílica o una combinación de ambas entidades.

Se presenta el caso de un paciente de 4 años, con lesiones clínicas e histopatológicas sugestivas de eritema elevatum diutinum, con afectación extensa en la piel y compromiso laríngeo.

PALABRAS CLAVE: vasculitis leucocitoclástica cutánea, niño, membrana mucosa, laringe.

\section{SUMMARY}

Erythema elevatum diutinum is a rare, chronic inflammatory dermatosis, characterized by erythematous brown and purple papules and nodules on extensor surfaces with a characteristic clinical pattern. Generally, it is associated with infectious, autoimmune diseases and hematological malignancies. For some authors it is considered a leukocytoclastic vasculitis and for others it is within the spectrum of neutrophilic dermatosis or a combination of both entities.

We report a case of a 4 year-old-patient with suggestive clinical and histopathological lesions of erythema elevatum diutinum, with extensive skin and laryngeal involvement.

KEY WORDS: Cutaneous leukocytoclastic vasculitis, child, mucous membrane, larynx.
Correspondencia:

Tatiana María Restrepo-Castaño

Email:

rpotati@hotmail.com

Recibido: 01/02/15

Aceptado: 17/10/18

Conflictos de interés:

No se reportan conflictos de interés.

Financiación:

Ninguna. 


\section{CASO CLIINICO}

Se presenta el caso de un paciente varón de 4 años, natural y residente en San Vicente, Antioquia, Colombia, quien consulta al hospital local por un cuadro de ocho días de evolución de tos, rinorrea, fiebre subjetiva y lesión costrosa en el dorso de la mano izquierda. En el hospital formulan el diagnóstico de impétigo vulgar asociado a cuadro gripal y ordenan tratamiento con cefalexina oral de forma ambulatoria.

Cuatro días después, asiste nuevamente al hospital regional por un aumento de las lesiones en la piel, con compromiso de las fosas nasales, la mucosa oral, las extremidades superiores e inferiores y los glúteos. Además, con estridor laríngeo y disfonía, por lo que se inicia el tratamiento con clindamicina, se realiza una biopsia de piel y se decide remitir a tercer nivel de atención.

A la revisión por sistemas, la madre del paciente refiere que es el primer episodio y niega tener familiares con cuadros similares. El paciente es producto del primer embarazo, un parto vértice espontáneo, a término, sin complicaciones, sin antecedentes personales o familiares de importancia.

A la exploración física, se encuentra que el paciente está en regulares condiciones generales, con disfonía, estridor inspiratorio y afebril. En la piel presenta pápulas normocrómicas y placas eritematosas descamativas, con algunos nódulos con bordes sobreelevados y pseudovesiculación, además de lesiones tumorales con descamación en la periferia y costra central. Hay compromiso de las superficies extensoras, como los codos, el dorso de las manos, las fosas nasales (figura 1), las rodillas, la cara posterior de las piernas, las fosas poplíteas y los glúteos. También se observan algunas erosiones no dolorosas en la mucosa oral, en la lengua, el paladar duro y blando y el labio superior.

El paciente es valorado por otorrinolaringología por compromiso de la vía respiratoria superior. Se lleva a cabo una laringotraqueobroncoscopia, que encuentra lesiones en la lengua, las amígdalas, la cavidad oral, la faringe y la laringe, con edema y obstrucción posterior en los repliegues aritenoepiglóticos. La tráquea y los bronquios fuentes están sanos, aunque por el compromiso de las estructuras laríngeas, con alto riesgo de obstrucción de la vía respiratoria y de insuficiencia respiratoria, se decide realizar la traqueostomía.

En los paraclínicos, se evidencia una leucocitosis leve con neutrofilia, además de un perfil infeccioso con virus hepatótropos negativo, $\mathrm{p}$ y c ANCAS negativos y serología para sífilis no reactiva. El ELISA para virus de la inmunodeficiencia humana (VIH) es negativo y la función renal, así como la glucosa-6-fosfato-deshidrogenasa y la electroforesis de proteínas no presentan alteraciones.

En los resultados de las biopsias de la piel tomadas inicialmente se reporta un infiltrado inflamatorio neu-

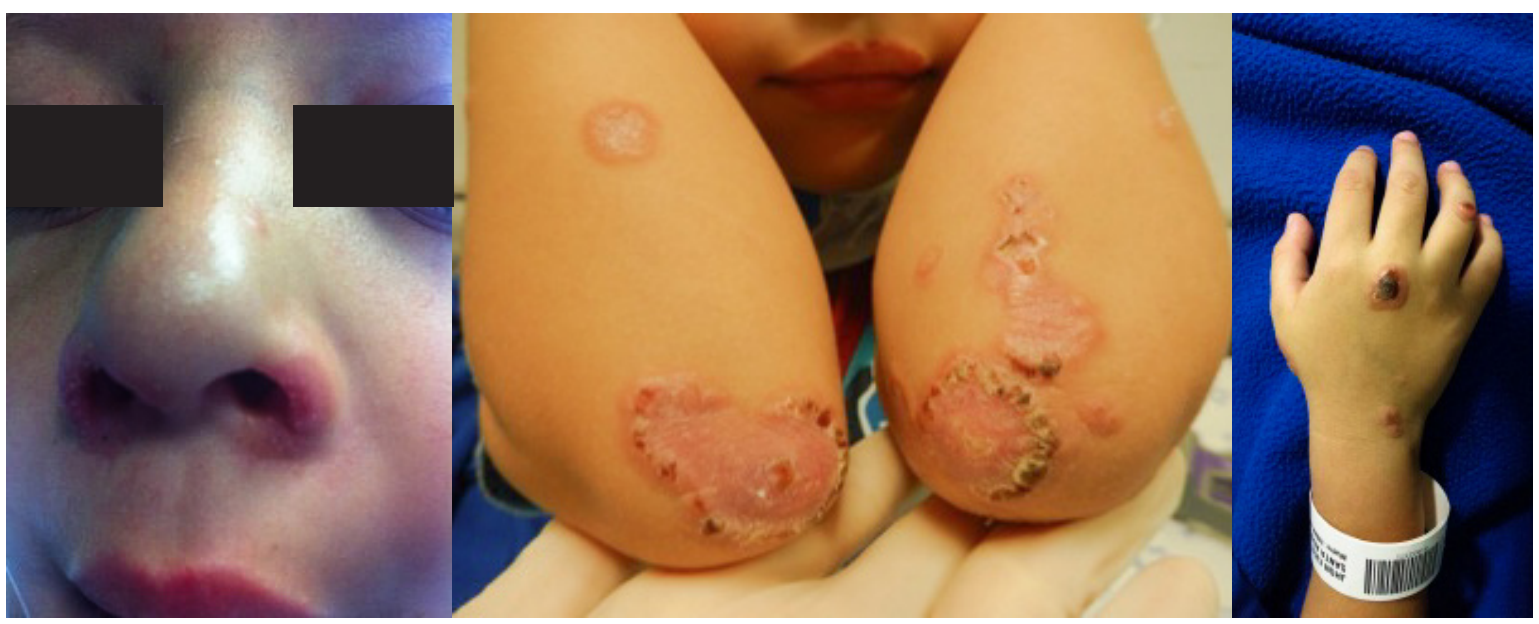

Figura 1. Nódulos y placas eritematosas con borde descamativo y costras en dorso de mano, codos y erosiones en fosas nasales. 
trofílico denso que, junto con algunas de las características de las lesiones cutáneas, sugería como posibilidades diagnósticas el síndrome de Sweet, la dermatitis herpetiforme o la dermatosis lineal por inmunoglobulina A (IgA).

Sin embargo, después de realizar nuevas biopsias de la piel para esclarecer el diagnóstico, se reporta la presencia de hiperplasia epidérmica y de necrosis fibrinoide de la pared vascular en la dermis, con infiltración de neutrófilos. El tejido conectivo perivenular tiene fibrina e infiltrado inflamatorio mixto, con predominio de neutrófilos, además de leucocitoclastia y fibrosis inicial (figura 2). El estudio de inmunofluorescencia directa (IFD) en la piel no muestra depósitos de inmunoglobulinas ni complemento.

Basados en la historia clínica del paciente, los hallazgos a la exploración física, la evolución, los resultados del estudio de histopatología y la IFD negativa, se formula el diagnóstico de eritema elevatum diutinum (EED) con manifestaciones en la piel, las mucosas y compromiso laríngeo.

Se inicia el tratamiento con clobetasol tópico en las lesiones $\mathrm{y}$, posteriormente, se administra prednisona en
$7,5 \mathrm{mg} / \mathrm{d}$.

El paciente es valorado ulteriormente por reumatología, hematología y oftalmología, en un hospital de alta complejidad, en donde descartan otras enfermedades asociadas al cuadro clínico o si hay compromiso de otras superficies mucosas.

Con los resultados normales de glucosa-6-fosfatodeshidrogenasa, se decide administrar dapsona en 25 $\mathrm{mg} / \mathrm{d}$, con excelente respuesta que inicia a las 48 horas de tratamiento. El paciente continúa con la terapia ordenada y con resolución total de las lesiones.

Un mes y medio después del alta hospitalaria, el paciente sufre una recaída, con menor cantidad de lesiones asociada a un cuadro gripal; sin embargo, en esta oportunidad, solamente hubo compromiso de la piel.

Se inicia el desmonte progresivo de la dapsona por la mejoría clínica vista y por la disminución no significativa de los valores de hemoglobina (13,5 a 12,7 g/dl), hasta llegar a los $12,5 \mathrm{mg}$ interdiarios, dosis con la que se encuentra actualmente, sin nuevas recidivas (figura 3).

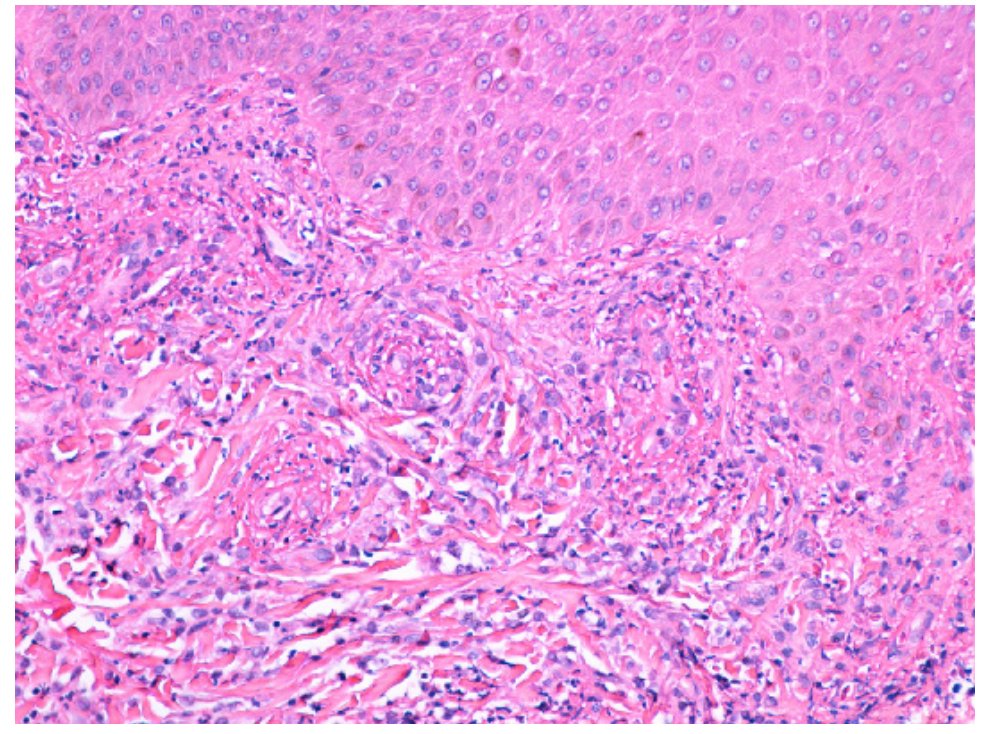

Figura 2. Hiperplasia epidérmica, necrosis fibrinoide de la pared vascular con infiltración de neutrófilos en la dermis. Fibrina e infiltrado inflamatorio mixto con predominio de neutrófilos en tejido conectivo, leucocitoclastia y fibrosis inicial. 


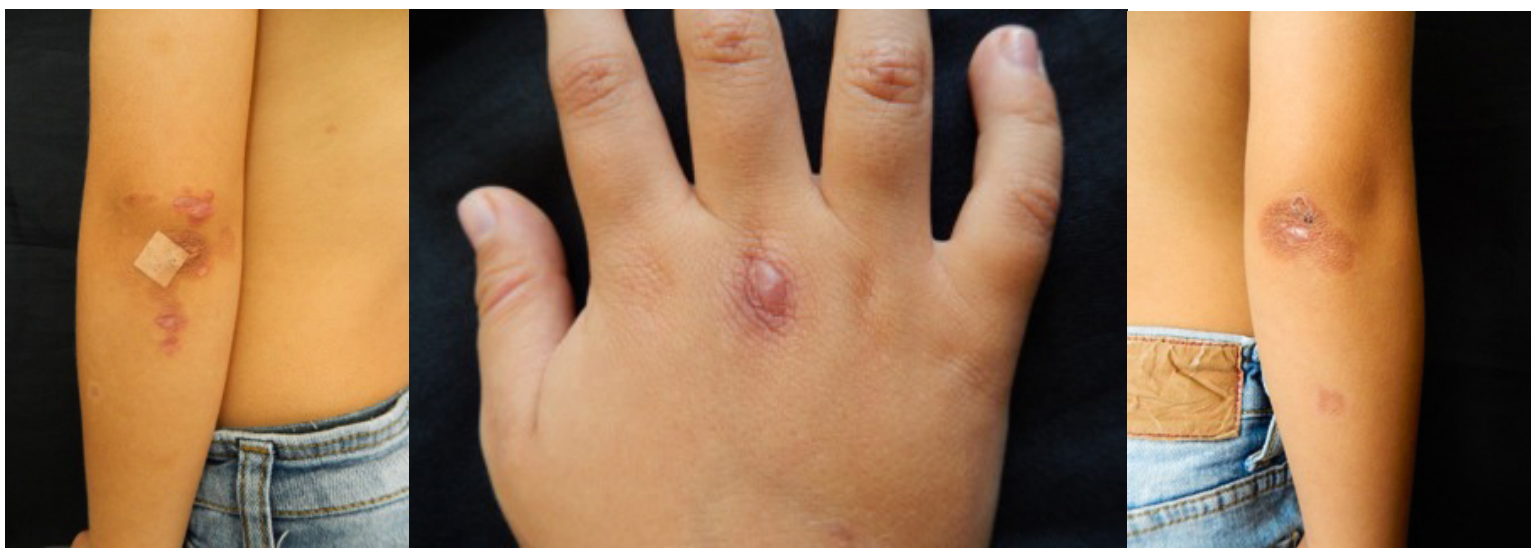

Figura 3. Cicatrices residuales en codos y dorso de mano después de tratamiento con dapsona.

\section{DISCUSIÓN}

El EED es considerado, por algunos autores, como una vasculitis leucocitoclástica crónica de pequeños vasos no asociada a ANCAS y, por otros, como una dermatosis neutrofílica o una combinación de ambas entidades. Presenta lesiones cutáneas con un patrón clínico característico por su localización en las superficies extensoras. En gran parte de los casos está asociado a enfermedades infecciosas, autoinmunes o neoplasias hematológicas ${ }^{(1,2)}$.

El EED es una entidad poco frecuente, con aproximadamente 250 casos reportados en la literatura hasta el año 2011, y es aún más escasa su presentación en niños. Puede aparecer a cualquier edad (3), pero es mayor la prevalencia entre la cuarta y la séptima década de vida. Los casos en personas más jóvenes usualmente se asocian a algún tipo de inmunodeficiencia. Afecta por igual a ambos géneros y no hay predilección racial $^{(2,4)}$.

En términos generales, la fisiopatología del EED es desconocida, pero parece estar implicada una reacción de hipersensibilidad local de tipo III. Hay sobreexpresión de un antígeno, en gran parte de los casos por las comorbilidades asociadas, lo que desencadena una reacción antígeno-anticuerpo con activación del complemento y formación de complejos inmunes circulantes, que se depositan en la pared de los pequeños vasos sanguíneos, que lleva a la destrucción vascular y, por último, a fibrosis ${ }^{(2)}$.

Clínicamente, el EED se manifiestan como pápulas, placas y nódulos simétricos eritematosos, de color violáceo o marrón, que pueden evolucionar a ampollas, vesículas y erosiones. Algunas de estas pueden presentar una configuración en diana, ser asintomáticas, dolorosas o pruriginosas. Aunque frecuentemente apa- recen en superficies extensoras, también se pueden observar en los glúteos y en la región posterior de las extremidades ${ }^{(5)}$, o en localizaciones atípicas como el rostro y el pabellón auricular. Todas estas zonas anatómicas estaban comprometidas en el paciente del caso descrito. En ocasiones, se asocian a síntomas sistémicos, como la fiebre y las artralgias, y su evolución suele ser crónica y recurrente, con resolución de 5 a 10 años en la mayoría de los $\operatorname{casos}^{(1,2)}$.

En cuanto a las manifestaciones extracutáneas del EED, la más descrita es el compromiso ocular, que puede presentarse como escleritis nodular, panuveítis y queratitis. El compromiso de otras superficies mucosas es muy raro, con pocos casos reportados en la literatura. De estos, solamente se encontraron cuatro pacientes con afectación de las mucosas: el primero, un adulto con compromiso laríngeo y peneano ${ }^{(6)}$; el segundo, un niño de 7 años, con infecciones estreptocócicas recurrentes, que presentó lesiones en la piel y la mucosa oral; el tercero, una niña de 3 años, con infección crónica del tracto respiratorio superior e hipergammaglobulinemia D, con lesiones extensas en las superficies extensoras, los glúteos, el rostro, las orejas, la lengua y la cavidad oral (7), similar a los hallazgos encontrados en el paciente del presente estudio; y el cuarto, una mujer de 19 años, con lesiones gastrointestinales, en las extremidades y en la mucosa oral, en la que se formuló un diagnóstico de superposición de EED y síndrome de Sweet ${ }^{(8)}$.

Cuando hay lesiones en las mucosas, probablemente se deban a un fenómeno de vasculitis y a una menor capacidad de los neutrófilos para combatir las bacte$\operatorname{rias}^{(6,7)}$.

En cuanto a las principales enfermedades asociadas al EED, están: enfermedades autoinmunes, infecciones, principalmente por VIH, virus hepatótropos y estrepto- 
cocos; neoplasias, de las cuales, las más relacionadas son la paraproteinemia IgA y el síndrome mielodisplásico; y, por último, los medicamentos tales como los antituberculosos, el cisplatino y la eritropoyetina. En el caso que se presenta, todos estos factores fueron descartados $^{(2)}$.

El diagnóstico se basa en el curso de la enfermedad, que generalmente es prolongado, con recurrencias ocasionales, manifestaciones clínicas características por su localización y, finalmente, hallazgos histopatológicos que evidencian vasculitis leucocitoclástica con infiltrado neutrofílico y, en fases más avanzadas, aparición de una fibrosis perivascular progresiva ${ }^{(1)}$.

En lo que respecta a los principales diagnósticos diferenciales del EED, están la dermatitis herpetiforme, la dermatosis lineal por IgA, el lupus ampolloso y el síndrome de Sweet ampolloso.

Es importante resaltar que, en gran parte de los casos, pueden coexistir los hallazgos clínicos e histológicos de distintas dermatosis neutrofílicas. Se han reportado algunos casos en la literatura de superposición de síndrome de Sweet o dermatitis herpetiforme con EED, lo que dificultad aún más el diagnóstico ${ }^{(8)}$. Es aquí donde la histopatología desempeña un papel fundamental, porque pese a que en todas estas entidades se puede observar un infiltrado neutrofílico, la coexistencia de este con vasculitis leucocitoclástica se da solamente en el EED. Igualmente, la inmunofluorescencia directa ayuda a descartar otras enfermedades, como la dermatosis lineal por IgA y la dermatitis herpetiforme $(5,9,10)$. Las lesiones clínicas características, los hallazgos de vasculitis leucocitoclástica con infiltrado neutrofílico en la histopatología y la inmunofluorescencia directa negativa apoyaron el diagnóstico en el paciente del presente estudio $^{(2)}$.

El tratamiento de elección para el manejo de esta entidad es la dapsona, por sus propiedades inhibitorias sobre los neutrófilos. En términos generales, los pacientes responden de forma notoria en 48 horas, como en el caso aquí presentado; sin embargo, no tratar la causa de la enfermedad y, por ende, la suspensión del medicamento pueden producir recaídas ${ }^{(2)}$. Otras opciones terapéuticas descritas son la niacinamida, las tetraciclinas, los esteroides sistémicos, tópicos o intralesionales, la clofazimina, la ciclofosfamida e incluso los procedimientos quirúrgicos cuando las lesiones son muy grandes e intratables ${ }^{(1,2,11)}$.

En la literatura, solamente se encontró un caso reportado de un adulto con EED y compromiso laríngeo, que respondió adecuadamente al manejo con dapsona y esteroides sistémicos ${ }^{(6)}$. Este sería, entonces y hasta ahora, el segundo caso informado de un paciente con esta entidad y compromiso laríngeo.

\section{CONCLUSIÓN}

Se destaca la importancia de este caso clínico al considerar al eritema elevatum diutinum (o eritema elevado persistente o diutino; EED) como una forma distintiva de vasculitis cutánea, que puede llegar a presentar compromiso mucocutáneo extenso, por lo que es necesario un abordaje interdisciplinario, la investigación de las causas subyacentes y el tratamiento oportuno.

\section{REFERENCIAS}

1. Prat L, Bouaziz JD, Wallach D, Vignon-Pennamen MD, Bagot M. Neutrophilic dermatoses as systemic diseases. Clin Dermatol. 2014;32(3):376-88. doi: 10.1016/j.clindermatol.2013.11.004.

2. Shinkai K, Fox LP. Cutaneous vasculitis. En: Bolognia J, Jorizzo J, Schaffer J (editores). Dermatology. $3 \cdot^{a}$ edición. Filadelfia: Elsevier Saunders; 2012. p. 385-410.

3. Wang T, Liu H, Wang L, Guo Z, Li L. An unusual case of Sweet syndrome in a child: overlapping presentation with erythema elevatum diutinum. Am J Dermatopathol. 2014;36(6):e114-6. doi: 10.1097/DAD.oooooooooooooo26.

4. Wahl CE, Bouldin MB, Gibson LE. Erythema elevatum diutinum: clinical, histopathologic, and immunohistochemical characteristics of six patients. Am J Dermatopathol. 2005;27(5):397-400.

5. Chandrasekaran SS, Rai R, Vedachalam S, Dorairaj L, Palaniraman S. Erythema elevatum diutinum in association with dermatitis herpetiformis. Indian Dermatol Online J. 2014;5(1):48-50. doi: 10.4103/2229-5178.126032.

6. Syuto T, Tago O, Kuriyama Y, Ishibuchi T, Sasahira $\mathrm{S}$, Nagai Y, et al. An unusual case of erythema elevatum diutinum with penile and laryngeal manifestations. Eur J Dermatol. 2014;24(1):96-7. doi: 10.1684/ejd.2013.2212.

7. Tomasini C, Seia Z, Dapavo P, Soro E, Addese C, Pippione M. Infantile erythema elevatum diutinum: report of a vesiculo-bullous case. Eur J Dermatol. 2006;16(6):683-6.

8. Evans AV, Sabroe RA, Setterfield J, Greaves MW. Erythema elevatum diutinum/Sweet's syndrome overlap with gastrointestinal and oral involvement. Br J Dermatol. 1999;141(4):766-7. doi: 10.1046/j.1365-2133.1999.03140.x.

9. Maruthappu T, Tharakaram S, Calonje E, Shirlaw PJ, Setterfield J. Erythema elevatum diutinum with oral ulceration. Br J Dermatol. 2012;167(1):222-4. doi: 10.1111/j.1365-2133.2012.10851.x. 
10. Ryan AJ, Hayes BD, Sheahan K, Collins P. Tender erythematous papules on the elbows, buttocks and knees. Clin Exp Dermatol. 2011;36(5):564-6. doi: 10.1111/j.1365-2230.2010.03997.x.

11. Ahmad S, Delarosa M, Kleinman W, Ahmad R. Primary Surgical Treatment of Erythema Elevatum Diutinum. J Hand Surg Am. 2018;So3635023(18)30342-3. doi: 10.1016/j.jhsa.2018.07.018. 